\title{
Hepatitis $C$ in the Russian Federation: challenges and future directions
}

\author{
This article was published in the following Dove Press journal: \\ Hepatic Medicine: Evidence and Research \\ 5 May 2016 \\ Number of times this article has been viewed
}

\section{Sergey Mukomolov ${ }^{\dagger}$ Galina Trifonova \\ Irina Levakova \\ Daria Bolsun \\ Eugenia Krivanogova}

Department of Epidemiology, SaintPetersburg Pasteur Institute, Saint Petersburg, the Russian Federation

†Professor Sergey Mukomolov passed away on June I, 2015
Correspondence: Galina Trifonova Department of Epidemiology, SaintPetersburg Pasteur Institute, I 4 Mira Street, 19710I Saint Petersburg, the Russian Federation

$\mathrm{Tel}+78122331762$

$\mathrm{Fax}+78122329217$

EmailTrifonovaGT@pasteurorg.ru
Abstract: Hepatitis $\mathrm{C}$ virus (HCV) infection is one of the most prevalent health problems in the world. Official registration of HCV infections in the Russian Federation started in 1994. Two clinical forms of infection - acute and chronic hepatitis $\mathrm{C}$ - are registered separately. Moreover, the HCV national surveillance system also includes reports from laboratories on results from testing $\sim 20$ population risk groups for antibodies to $\mathrm{HCV}$; approximately 15-16 million tests are performed annually. Modern epidemiological features of HCV infection in the Russian Federation are characterized by low incidence of the acute form of infection (acute HCV; one to two per 100,000) and a dramatic increase in chronic HCV (CHCV) cases. In 2013, the average nationwide rate of newly detected $\mathrm{CHCV}$ cases was 39.3/100,000. In the same year, the prevalence of CHCV demonstrating an accumulation of chronically infected patients in the country was much higher $-335.8 / 100,000$ Four risk groups were identified as greatly affected by HCV, which were demonstrated by a high prevalence of antibodies to $\mathrm{HCV}$ : newborns from chronically infected women, persons from correctional facilities, patients with chronic liver diseases, and clients from clinics for sexually transmitted disease patients and drug users. It was found that several HCV genotypes circulated in different regions of the country; HCV1b had a prevalence of $55 \%-80 \%$ in almost every part of the country. However, in St Petersburg during the final decade of the last century and from 2001-2005, HCV3a subtype expanded circulation among young people due to increased intravenous drug addiction. Intravenous drug users were the major cause of a higher registration of double infection, with two different virus subtypes, and the appearance in Russia of new recombinant virus RF_2k/1b. It can be concluded that $\mathrm{CHCV}$ infection should be a focus of the health care system in Russia because serious epidemics of liver cirrhosis and hepatocellular carcinoma will be seen in the near future that will require urgent preventive and therapeutic measures.

Keywords: hepatitis C, epidemiology, the Russian Federation, chronic hepatitis C

\section{Introduction}

In 2014, researchers and medical personnel celebrated the 25th anniversary of the discovery of hepatitis $\mathrm{C}$ virus (HCV). The first publication on the new virus genome appeared in $1989 .{ }^{1}$ After that, comprehensive study of new HCV and related disease began, including diagnostics, pathogenesis, and epidemiology. The official registration of acute HCV (AHCV) infection in the Russian Federation began in 1994. The standard case definition for AHCV was adapted from World Health Organization recommendations. ${ }^{2}$ It is necessary to diagnose AHCV based on epidemiological and clinicobiochemical findings, such as the presence of newly identified markers of HCV - antibodies to $\mathrm{HCV}$ (anti-HCV) and HCV RNA. Anti-HCV detection has a special diagnostic value for acute hepatitis discrimination in disease dynamic (after 4-6 weeks) after negative 
results of this marker in the early stage of the disease. The presence of HCV RNA in the phase of "serological window" is an important diagnostic criterion.

Five years later (1999), the registration of chronic $\mathrm{HCV}$ (CHCV) cases also began in the Russian Federation. Moreover, since the beginning, all laboratories dealing with virology and clinical diagnostics reported on the testing for anti-HCV and registered all positive results.

The aim of the current review was to summarize available epidemiological data and to reveal the main manifestation of the epidemic process of HCV infection in the Russian Federation in the modern period.

Having a territory of $17,098,246 \mathrm{~km}^{2}$, Russia is the largest country in the world, covering more than one-eighth of the Earth's inhabited land area. Russia is also the world's ninth most populous nation with 143 million people as of 2012 . According to the National Constitution, ${ }^{3}$ the country comprises 85 federal subjects, including 46 oblasts (provinces), 22 republics, and nine krais (same as oblasts). The "territory" designation is historic, originally given to frontier regions and later also to administrative units that comprised autonomous "okrugs" or autonomous "oblasts". All federal subjects are grouped into eight federal regions on geographical and economical principles: North-West, Central, Southern, NorthCaucasus, Volga, Ural, Siberian, Far East. It is important to analyze all types of infection by territories to define the scale of disease distribution and risk regions.

\section{Materials and methods}

We carried out the retrospective epidemiological analysis of morbidity rate (the incidence per 100,000) for AHCV and $\mathrm{CHCV}$ infections. More than 200,000 cases of AHCV infection and $\sim 700,000$ cases of $\mathrm{CHCV}$ infection that were registered in 1994-2013 in the country were included in the epidemiological analysis.

We studied the incidence by year, distribution among different federal territories, age group, risk group, the main route of transmission, and the factors of risk.

For analysis, data from the state statistical accounts ${ }^{4,5}$ of infectious morbidity rate (incidence) in the Russian Federation and analytical tables sent from the territories for AHCV and $\mathrm{CHCV}$ were used. For chronic cases, the mean incidence of newly detected patients who were registered in the current year was calculated. For $\mathrm{CHCV}$ cases, the prevalence rates for different years, age groups, and territories were also calculated.

This article also contains characteristics of HCV distribution in the Russian Federation based on the results of testing of different risk groups for anti-HCV in 2011-2013. For testing of the risk groups for anti-HCV, Russian commercial enzyme-linked immunosorbent assay (ELISA) kits were used predominantly.

Commercial HCV genotyping tests have been available in the Russian Federation since 2000. In this review, several studies were analyzed to describe genotype distribution in some regions of Russia.

\section{$\mathrm{AHCV}$ in the Russian Federation}

The dynamics of AHCV cases in Russia during 1994-2013 could be characterized by different trends (Figure 1), in different periods. For example, in 1994-2001, the epidemic curve rose, which reflected the active spread of $\mathrm{HCV}$ and increase in acute clinical cases. The maximum incidence rate was seen in 2001 reaching 22.2/100,000. From 2001

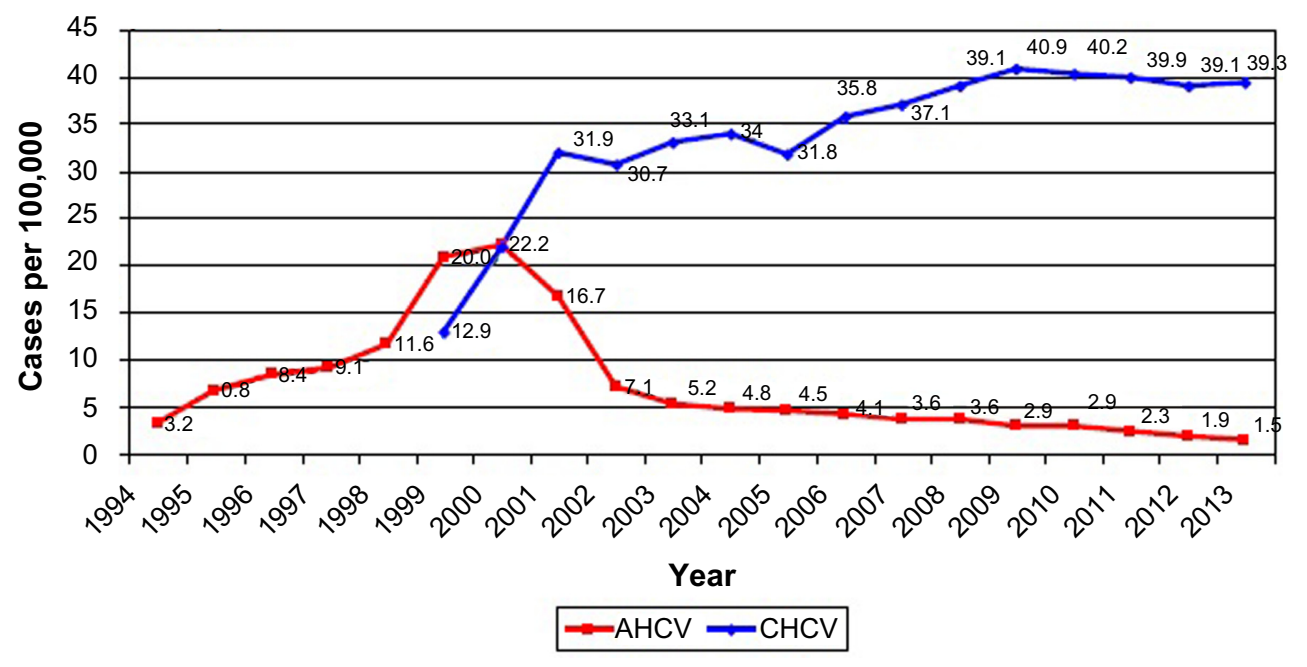

Figure I Registration of AHCV and CHCV cases in the Russian Federation in 1994-2013 per 100,000 of population. Abbreviations: $\mathrm{AHCV}$, acute hepatitis $\mathrm{C}$ virus; $\mathrm{CHCV}$, chronic hepatitis $\mathrm{C}$ virus. 
up to now, the epidemic curve looks like a descending line that characterizes the annual decrease in incidence due to a significant reduction of $\mathrm{HCV}$ infection. In general, AHCV incidence decreased more than ten times during 2002-2013. During 2013 the morbidity rate was only $1.5 / 100,000$.

Dynamics of AHCV incidence in different federal territories of Russia was absolutely synchronous during 1994-2013. The difference was only in the level of incidence and the year of maximal incidence. During 1999-2000, the maximal incidence was registered in North-West $(44.5 / 100,000)$ and Ural $(37.0 / 100,000)$ federal territories (Figure 2). Meaning that both territories had similar active risk factors for virus spread. Both territories kept their top ranges until 2007. After 2007, the maximum incidence was reported by Ural with comparatively high rates reaching 3.3-3.5/100,000. Minimal AHCV incidence rates were reported by provinces located in the Southern Federal Region during all years. In these territories, the maximum of AHCV reported was registered in $2001(10 / 100,000)$, ie, three to four times less than in North-West and Ural. Since the middle of 2000, the incidence was $<1.0 / 100,000$. In the North-Caucasian Federal Region, the incidence data are available only for the past 4 years and rates were lower than in all other federal regions during this period (2010-2013).

During all years, the AHCV incidence in children aged 0-14 years was significantly lower in comparison with rates in teenagers (15-19 years) and adults. For instance, in the period of active HCV spread in 1999-2000, the national incidence of AHCV in persons older than 15 years was $25 / 100,000$, but in children less than 14 years this rate was only $3 / 100,000$. In the present time, the age distribution of $\mathrm{AHCV}$ is characterized by very low incidence $(<1 / 100,000)$ in children and in adults older than 50 years. It is important to note that the third ranking position in the recorded incidence of $\mathrm{HCV}$ among children younger than 14 years of age takes into account children up to 1 year. In 2009 , the incidence rate in this age group was $4.2 / 100,000$, in $20122.8 / 100,000$, and in 2013, it fell to $1.5 / 100,000$. It should be noted that the proportion of children younger than 1 year in all cases of AHCV among children younger than 14 years does not fall $<50 \%$ in recent years. Reasons for this deserve a separate study. It should be emphasized that the diagnosis of a child younger than 1 year can be established only with the appropriate clinical and biochemical parameters and viral RNA detection. Antibodies to the $\mathrm{HCV}$ do not have diagnostic value for children up to 1 year.

The maximal level of AHCV in 2013 was registered in two age groups; 20-29 years and 30-39 years (Figure 3). Owing to such age distribution of AHCV cases, it is important to analyze the possible routes of virus transmission.

The information on routes of HCV transmission/risk factors is summarized in Figure 4 and includes data on 6,800 patients registered in 2011-2013 as AHCV cases. In children aged $0-14$ years, the principal significance has been the transmission of $\mathrm{HCV}$ from the mother with $\mathrm{CHCV}$ to her child during pregnancy or labor. The proportion of such transmission in the age group $0-14$ years was $67.4 \%$. The transmission routes were not determined in $21.1 \%$ of children.

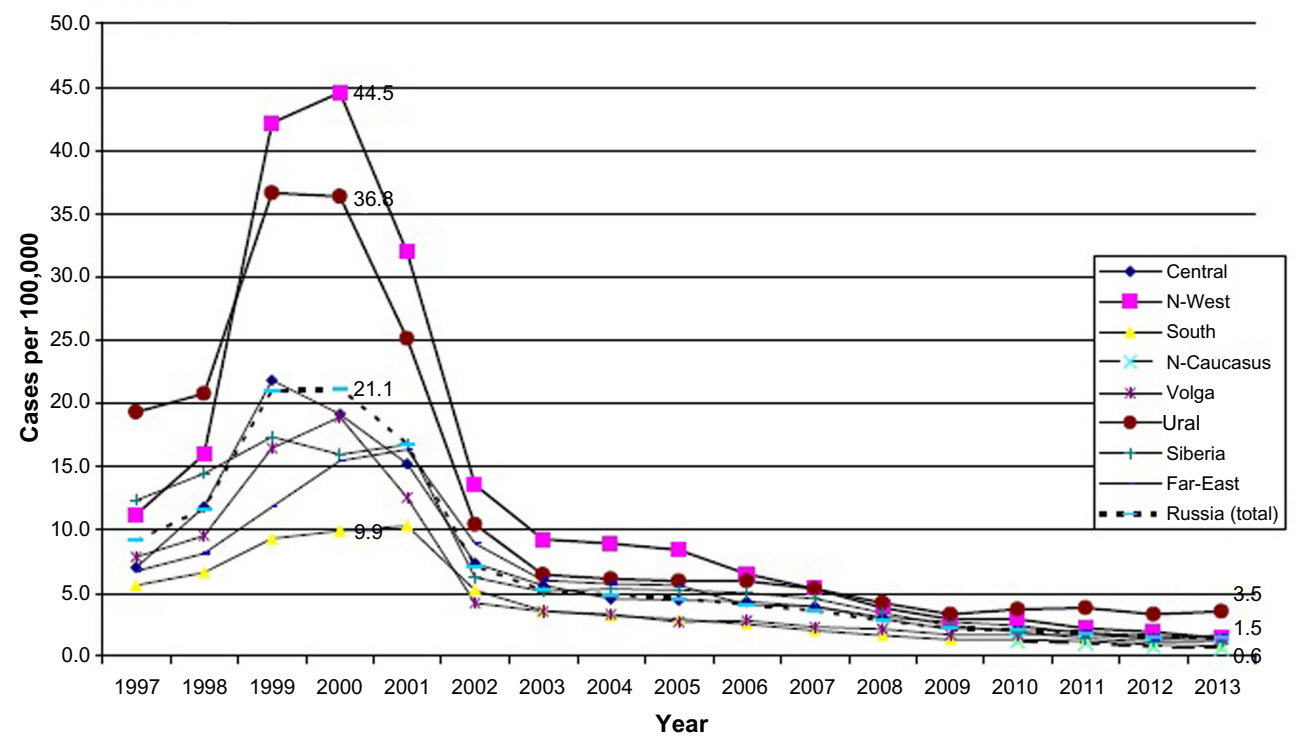

Figure 2 Acute hepatitis C incidence rates in different parts of the Russian Federation in 1997-2013. Abbreviations: N-West, North-West; N-Caucasus, North-Caucasus. 


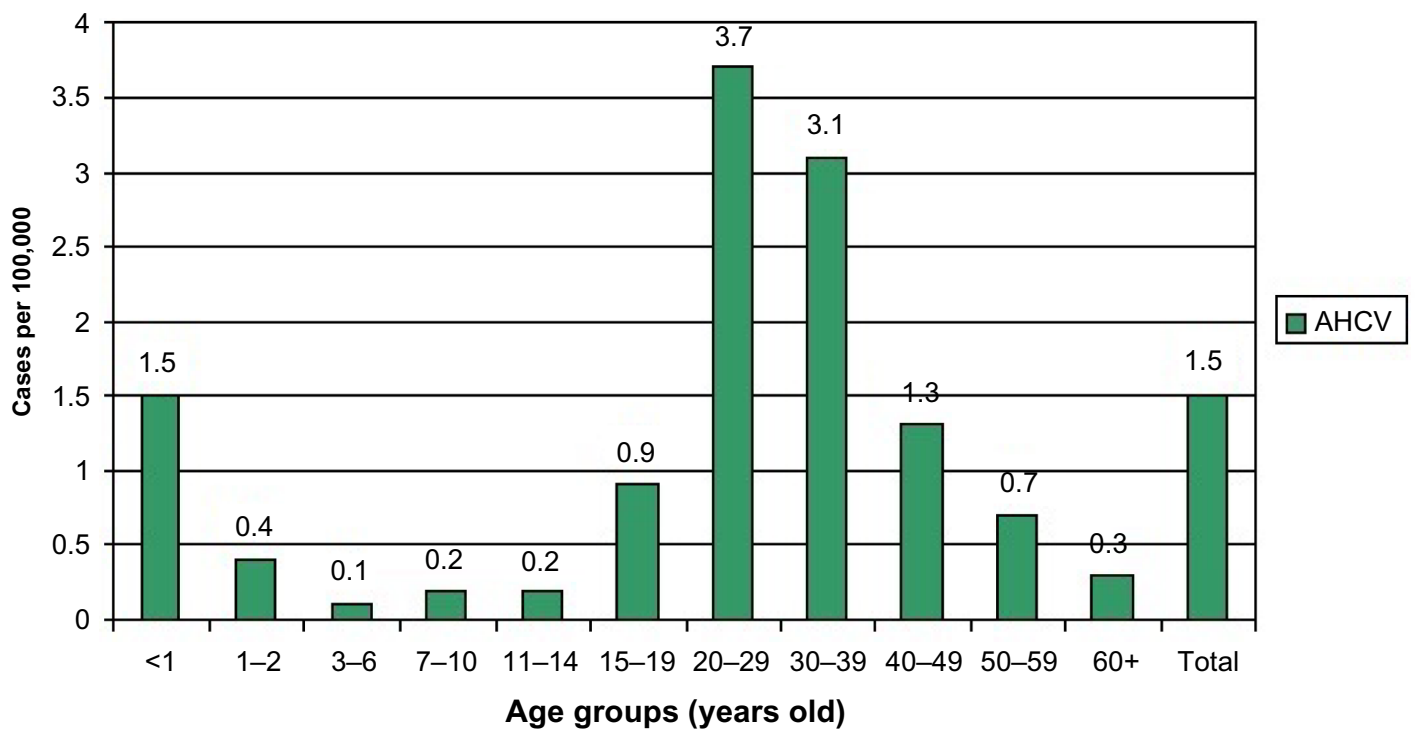

Figure 3 Acute hepatitis $C$ incidence in different age groups of population in the Russian Federation in 2013. Abbreviation: $\mathrm{AHCV}$, acute hepatitis $\mathrm{C}$ virus.

The analysis of data about likely routes routes of HCV infection and risk factors the 3 year period showed that the main route of transmission in children younger than 14 years is vertical, which is caused by children younger than 1 year. Vertical HCV transmission requires careful justification using modern molecular-biological methods of diagnosis. These materials confirm that the problem of HCV vertical transmission exists on site and medical professional should pay attention to it.

In adults 20-39 years, three main risks factors were documented by epidemiological investigation. The most important risk factor is sexual contact with probable source of infection (32.6\%); the second significant risk was connected with sharing needles and syringes during intravenous drug use (21.7\%); and the third risk factor was mainly related to cosmetic procedures, including tattooing and piercing (7.6\%). It is important to note that in $37.5 \%$ of patients, risk factors for HCV transmission remained unknown. This percentage of patients was more than among the children $0-14$ years $(21.1 \%)$. The poorest results of epidemiological investigations were in adults older than 40 years because risk factors were not determined in $66.7 \%$ of cases. In this age group, the most significant risk factors were sexual contacts $(17.7 \%)$ and cosmetic procedures $(9.0 \%)$. It should be emphasized that drug use as a risk factor in this age group was reported only in $3.8 \%$ of cases - almost six times less than in the younger adult group of 20-39 years.

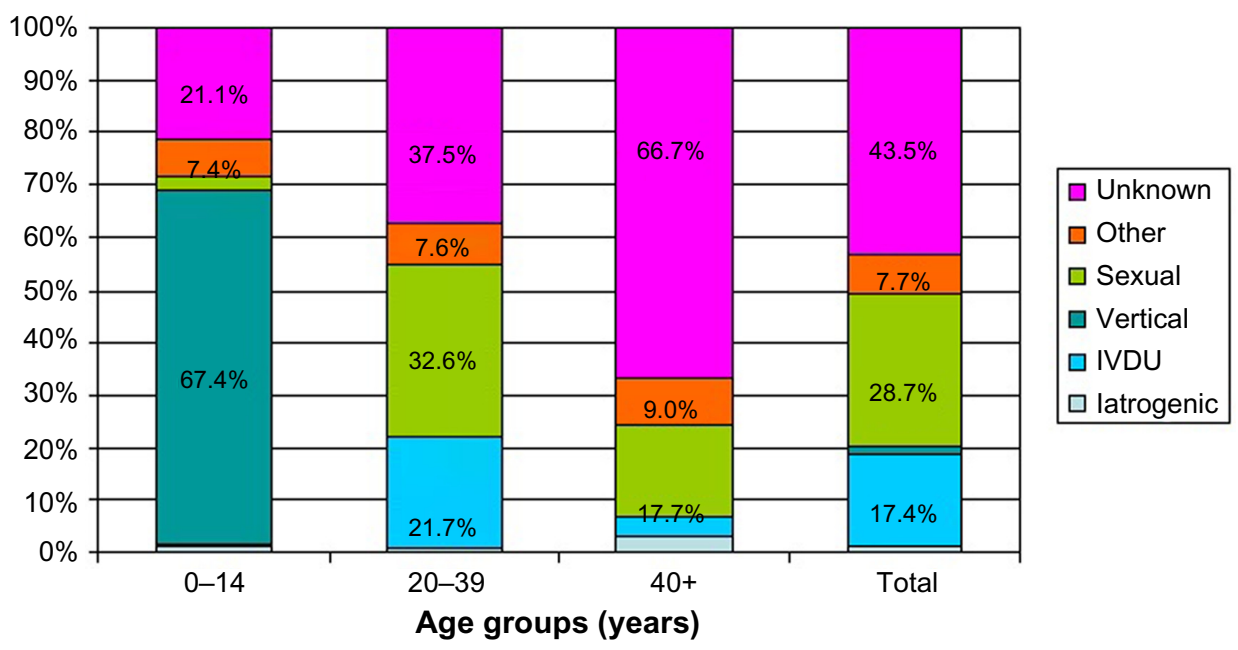

Figure 4 Structure of possible HCV routes of transmission in the Russian Federation in 20II-20I3.

Abbreviations: HCV, hepatitis C virus; IVDU, intravenous drug user. 
It is well known that different medical procedures are high risk for HCT transmission. In general, medical manipulations did not play any visible role in HCV transmission in the modern time. The proportion of medical manipulations as risk factor was only $\sim 1 \%$ of cases. The biggest proportion of this risk factor reaching $2.9 \%$ was found in persons older than 40 years.

Thus, it is important to emphasize, probable risk factors of HCV transmission in children were vertical transmission, involving children aged younger than 1 year in the Russian Federation in 2011-2013. It required careful justification using modern molecular-biological methods of diagnosis, and the obtained data confirm that the problem of $\mathrm{HCV}$ vertical transmission existed in Russia.

In adults, the most significant risk factor was intravenous drug use in the age group of 20-39 years. Iatrogenic transmission played a minimal role and was more visible in the group of persons older than 40 years.

The study of HCV routes of transmission and risk factors among children aged $0-14$ years and adults is only preliminary, and requires detailed analysis over a longer period of time.

\section{$\mathrm{CHCV}$ in the Russian Federation}

The dynamics of registration of newly diagnosed CHCV cases, unlike $\mathrm{AHCV}$, is characterized by an ascending trend since 1999. The registration rate (incidence) for $\mathrm{CHCV}$ increased in the Russian Federation from 12.9/100,000 in
1999 to $39.3 / 100,000$ in 2013, ie, more than three times (Figure 1). In general, the morbidity rate maintained at 39-40/100,000 in the Russian Federation since 2008. Probably meaning that the maximum detection of new $\mathrm{CHCV}$ cases is already reached. The dynamic of newly detected $\mathrm{CHCV}$ cases in different federal territories varied significantly by rates and trends of morbidity. In three federal territories (Far East, Ural, and North-West), the $\mathrm{CHCV}$ incidence was higher than the average level in the country. The incidence of CHCV reached 47.2/100,000 (Far East), 48.3/100,000 (Ural), and 67.8/100,000 (North-West; Figure 5). The registration curve in the North-West has manifested ascending type, but in the Ural, the increase was interrupted in 2009 and then the decreasing trend became clear. During the last 2 years (2012-2013), CHCV registration the same as in Ural tendency was also registered in the Far East territory.

Trends of $\mathrm{CHCV}$ registration in the Volga and Siberia federal territories are similar to those in the whole country and could be characterized as ascending. In 2013, the CHCV incidence in the Volga territory was 41.2/100,000 and in Siberia 45.8/100,000. Three other federal territories had CHCV level less than the level in the whole country, but dynamic curves look different. For instance, the trend in the Central Federal Territory was ascending with $\mathrm{CHCV}$ incidence in 2013 equal to $32.6 / 100,000$. The curve in the Southern Territory could be described as plateaued with weak tendency to decrease (22.9/100,000 in 2013). Rates in North-Caucasus (data

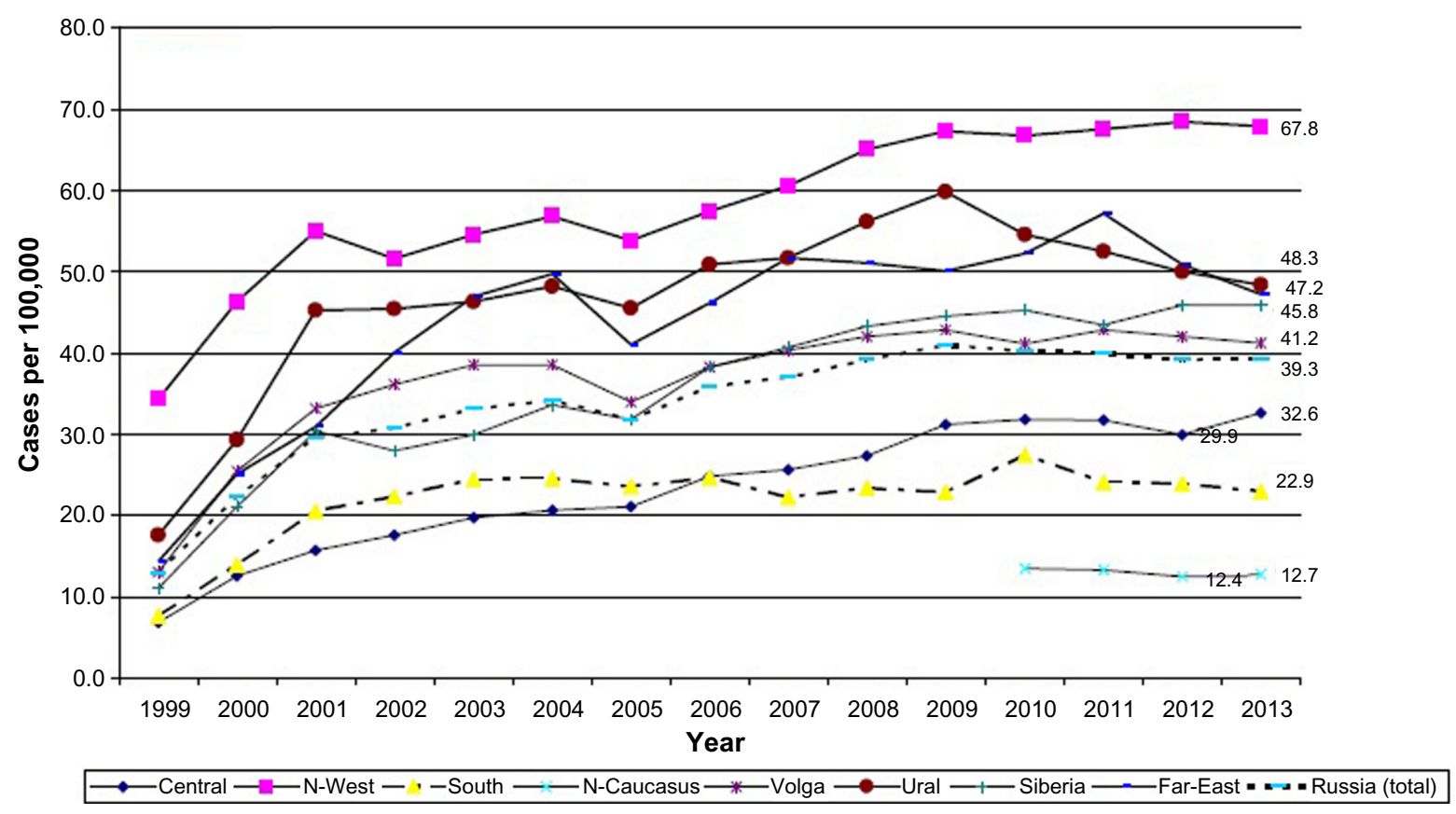

Figure 5 Newly detected cases of chronic hepatitis C registration in different parts of the Russian Federation in 1999-2013. 


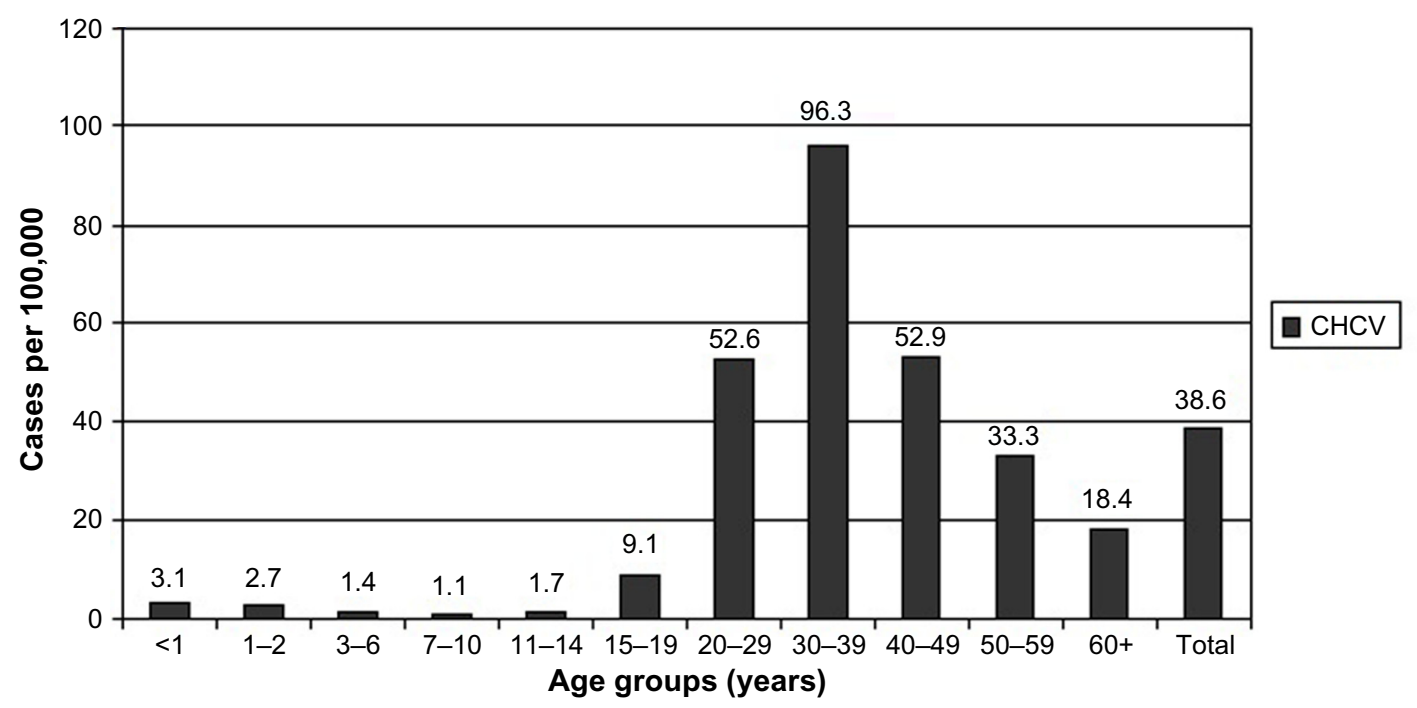

Figure 6 Newly registered cases of chronic hepatitis C in different age groups of population in the Russian Federation in 2013 (rates per 100,000). Abbreviation: $\mathrm{CHCV}$, chronic hepatitis $\mathrm{C}$ virus.

available for analysis only for the last 4 years) were stable, $\sim 12-13 / 100,000$. This is the lowest CHCV incidence in the country in 2011-2013.

The age distribution of newly registered $\mathrm{CHCV}$ cases is characterized by maximal rates in the age group $20-49$ years (Figure 6). The highest incidence reaching 96.3/100,000 was reported in 2013 among adults 30-39 years old. Two age groups (20-29 years and 40-49 years old) have shown the same rates $\sim 53 / 100,000$. Such age distribution of chronic cases reflects the epidemic situation of HCV spread at the end of 1990s. It should be noted that CHCV incidence in children is very low - one to three cases per 100,000 .
These data support the idea that HCV is not a children's infection.

In comparison with newly detected $\mathrm{CHCV}$ cases (incidence), the disease prevalence (accumulated cases) gives more complete vision of epidemiological situation in the territory.

In 2013, the CHCV prevalence in the country reached 335.8/100,000 (Figure 7). The highest CHCV prevalence was registered in the North-West region, Ural, and Far East $(670.4 / 100,000,587.5 / 100,000$, and 585.6/100,000, respectively). The CHCV prevalence in the Volga Federal Region was higher than the average country level $(425.9 / 100,000)$ and

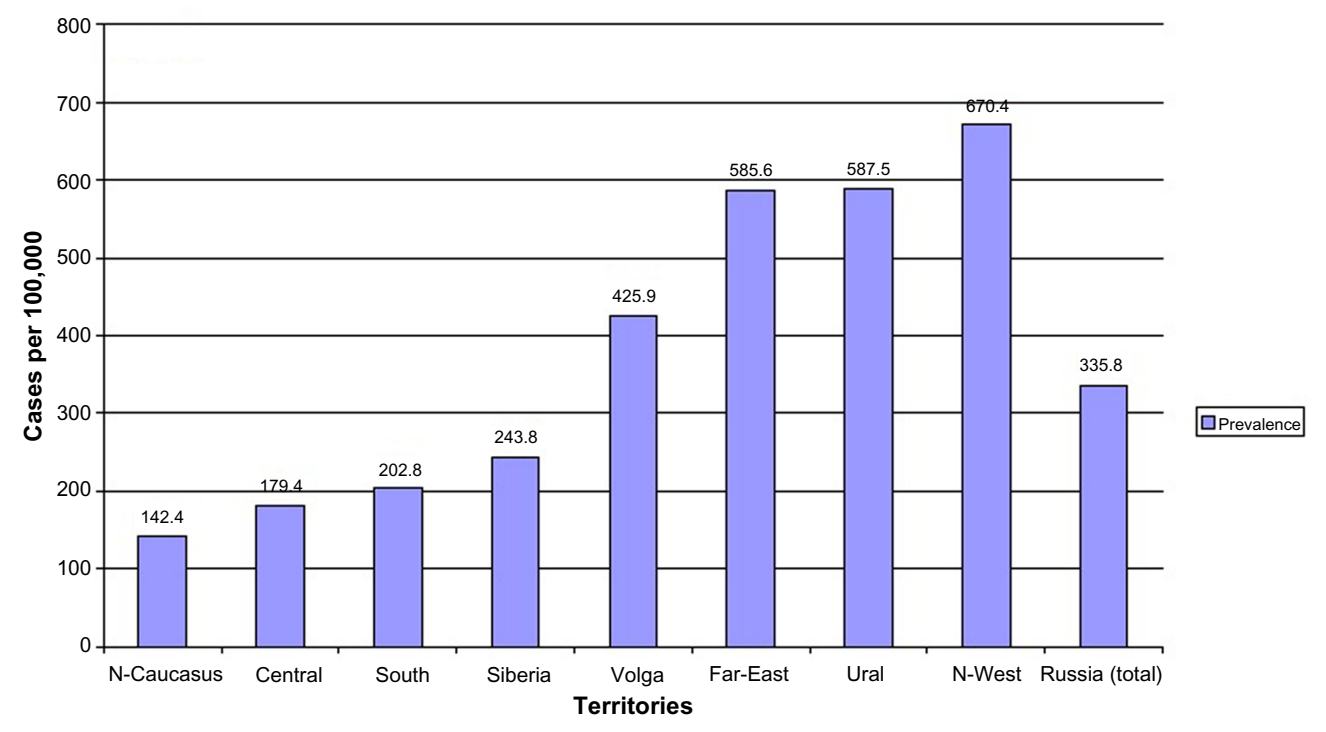

Figure 7 Prevalence of chronic hepatitis $C$ in different parts of the Russian Federation in 2013. Abbreviations: N-Caucasus, North-Caucasus; N-West, North-West. 


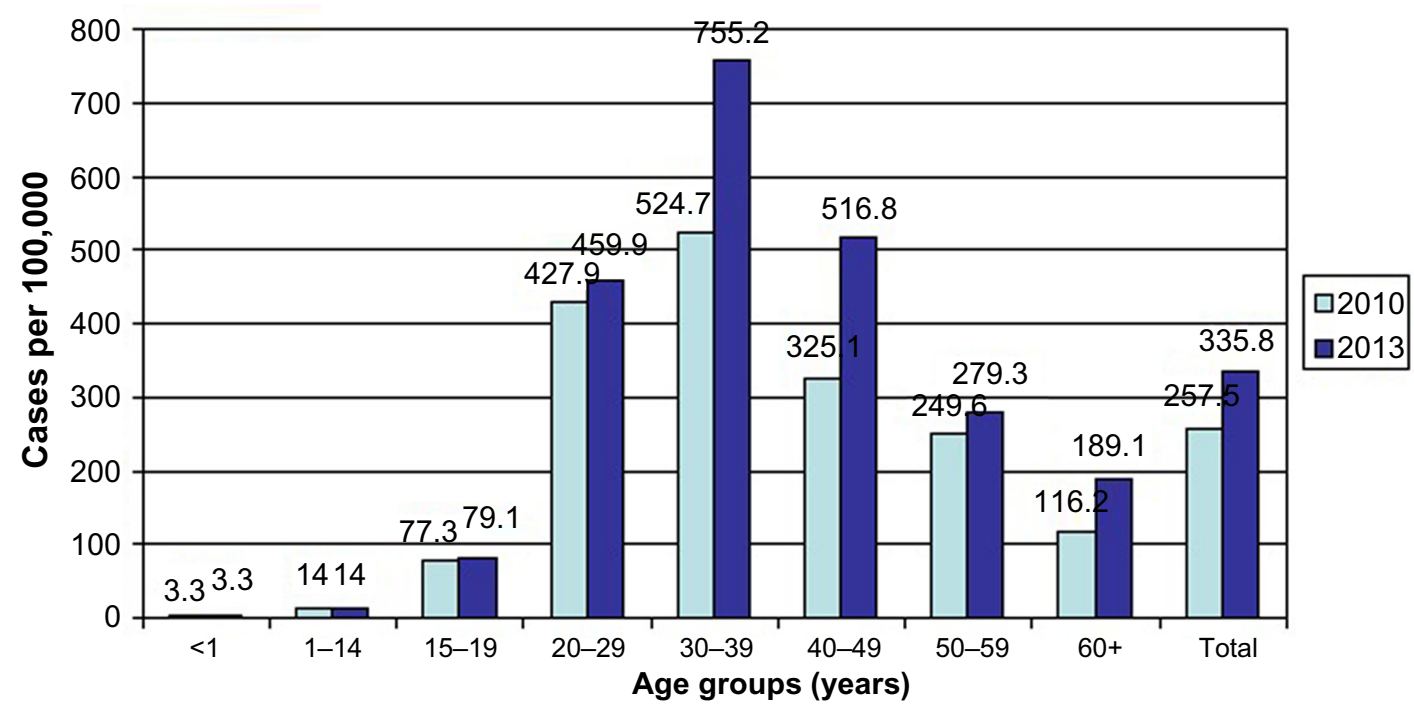

Figure 8 Prevalence of chronic hepatitis C cases in different age groups of the Russian Federation in 2010 and 2013.

in the remaining four regions, it was lower than the prevalence found in the whole country (range from 243.8/100,000 in Siberia to $142.4 / 100,000$ in North-Caucasus). In most administrative territories, the maximal $\mathrm{CHCV}$ prevalence was reported in the age group 30-39 years in 2013 (Figure 8). This correlates with AHCV age-specific incidence rates in 1999-2000 showing the highest levels in the age group $15-29$ years.

In age-specific structure of prevalence, the first rank also belongs to persons 30-39 years. The proportion of this age group was 32\% in 2013. In all the main territories in the country, the proportion of persons in the age group 30-39 years was the highest among all the $\mathrm{CHCV}$ cases. The second rank belonged to persons 20-29 years. The average proportion of this age group was $24 \%$ in the whole country with fluctuations from $20 \%$ to $29.5 \%$. The Far East and North-Caucasus regions could be excluded from the mentioned common age-specific structure because in these territories, the second rank among $\mathrm{CHCV}$ patients belonged to persons in the age group 40-49 years. In other territories, the persons of age group 40-49 years had only third rank with rates varying from $17 \%$ to $23 \%$. The proportion of children up to and including 14 years of age and teenagers $15-19$ years of age with $\mathrm{CHCV}$ did not exceed 3\% in total. This could demonstrate that children were involved in the HCV spread quite rarely.

Age-specific rates of $\mathrm{CHCV}$ designated as prevalence per 100,000 of population look unlike the age structure of cases. In 2013, the highest prevalence was reported in the age group 30-39 years. The average prevalence in this age group in the country reached $684 / 100,000$, but in three regions, these rates were even higher: Ural region
1,257/100,000, North-West region 1,179/100,000, and Volga region $944 / 100,000$. Such prevalence means that $\sim 1 \%$ of the population in this age group was infected with HCV. The second rank in half of the territories (NorthWest, Far East, South, North-Caucasus) in 2013 belonged to adults 40-49 years of age, but in other four territories (Ural, Volga, Siberia, and Central) to the age group of 20-29 years. Such distribution of territories by agespecific prevalence gives evidence concerning intensity of involvement of different age groups in HCV transmission during previous years. It should be noted that the $\mathrm{CHCV}$ prevalence in the age group 30-39 years was maximal in Ural and North-West regions. At the same time, the second rank in the Ural region belonged to the age group of 20-29 years $(842 / 100,000)$, but in the North-West region to the age group of $40-49$ years $(878 / 100,000)$. It is logical to assume that in the Ural region, the intensive spread of HCV took place in younger persons than in the North-West region in previous years. The fourth rank by CHCV prevalence belonged to persons of 50-59 years of age, but with different levels of rates. Relatively high levels similar to the average rate in the whole territory in the age group of 50-59 years were demonstrated by NorthWest $(567 / 100,000)$, Far East $(531 / 100,000)$, and South $(298 / 100,000)$ regions. The lowest $\mathrm{CHCV}$ prevalence was registered in children $0-14$ years of age.

\section{Frequency of anti-HCV in different risk groups}

Annually, $\sim 15-16$ million tests for anti-HCV are performed in 20 different population risk groups in the Russian 
A

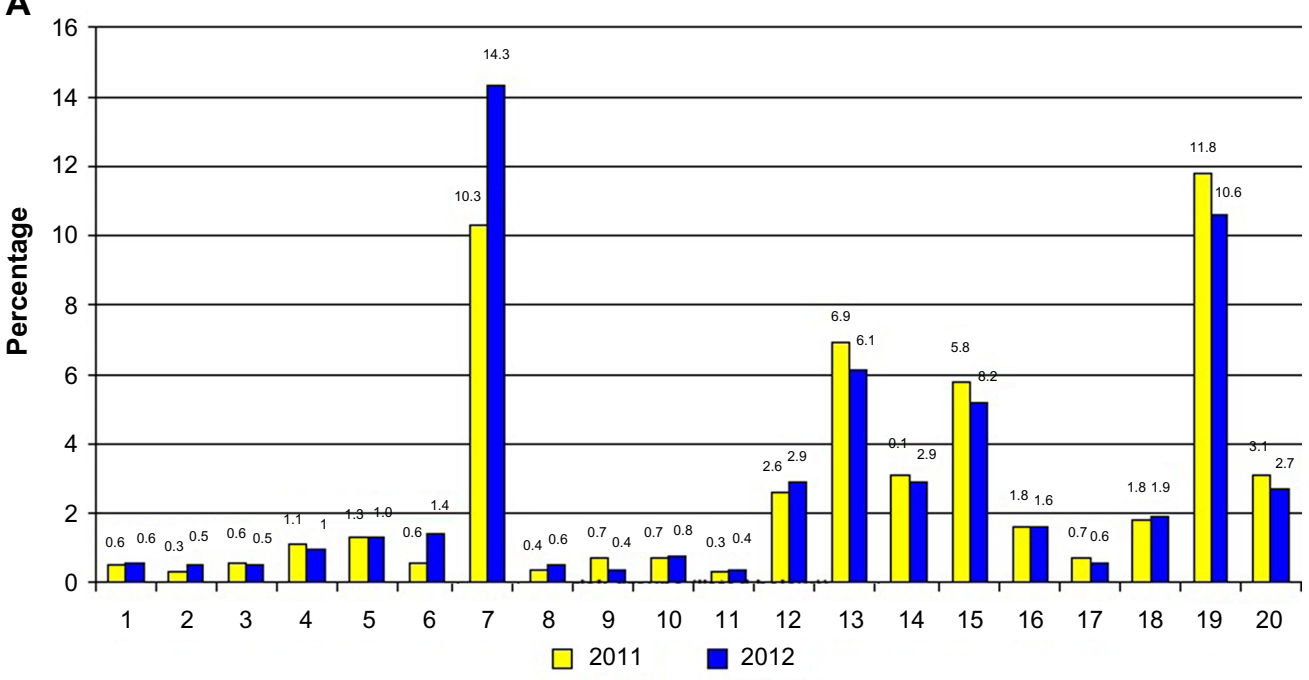

B

Risk groups (listed below)

\begin{tabular}{r|l|}
\hline No & \multicolumn{1}{|c|}{ List of risk groups mandatory tested for anti-HCV } \\
\hline 1 & Blood donors (total) \\
\hline 2 & Active blood donors \\
\hline 3 & Reserved blood donors \\
\hline 4 & Donors of bone marrow, sperm, other biological substrates \\
\hline 5 & Pregnant \\
\hline 6 & Recipients of blood and blood components \\
\hline 7 & Newborns from women suffering from AHCV (third trimester of pregnancy) and CHCV \\
\hline 8 & Personnel of blood banks \\
\hline 9 & Staff of hemodialysis units, renal transplantation, cardial and lung surgery, hematology \\
\hline 10 & Staff of clinical and diagnostic laboratories \\
\hline 11 & Personnel of surgery, urology, obstetrics and gynecology, anesthesiology, rehabilitation, stomatology, \\
\hline 12 & infectious diseases, emergency units etc \\
\hline 13 & Patients of hemodialysis units, renal transplantation, cardial and lung surgery, hematology \\
\hline 14 & Patients with chronic pathology (tuberculosis, oncology, psychoneurology etc) \\
\hline 15 & Patients from narcology and venereology departments and units \\
\hline 16 & Patients admitted to hospitals for planned surgery \\
\hline 17 & Persons and staff from special children institutions \\
\hline 18 & Household contact with AHCV, CHCV patients \\
\hline 19 & Persons from correctional institutions \\
\hline 20 & Others \\
\hline
\end{tabular}

Figure 9 Frequency of anti-HCV (A) in selected mandatory tested risk groups (B) in the Russian Federation in 201 I-2012.

Abbreviations: anti-HCV, antibodies to hepatitis $\mathrm{C}$ virus; $\mathrm{AHCV}$, acute hepatitis $\mathrm{C}$ virus; $\mathrm{CHCV}$, chronic hepatitis $\mathrm{C}$ virus; No, number.

Federation. Four risk groups had the highest anti-HCV rates in 2011-2012 (Figure 9): newborns from CHCV infected women $(10.3 \%-14.3 \%)$, persons from correctional facilities $(11.8 \%-10.6 \%)$, patients with chronic liver diseases (6.9\%-6.1\%), and clients from clinics for sexually transmitted disease patients and drug users $(5.8 \%-5.2 \%)$.

Relatively high anti-HCV rates were detected in patients from hemodialysis settings, units of renal transplantation, cardiovascular and lung surgery, and hematology $(2.6 \%-2.9 \%)$. This is rather a big group of patients who are under high risk of HCV transmission. In this group, special attention should be paid to the hemodialysis patients. In one independent study revealed that $25 \%-40 \%$ of patients in hemodialysis units were anti-HCV positive. ${ }^{6}$ Also patients with different kinds of chronic pathology had high proportion of anti-HCV positivity reaching $2.9 \%-3.1 \%$. Relatively high anti-HCV rates were detected in household contacts of CHCV patients $(1.8 \%-1.9 \%)$ and in patients who were admitted to hospital for planned surgery (1.6\%).

Pregnant women infected with HCV represent a special risk group because of possible virus transmission to newborns. Overall, in the country, anti-HCV was detected in 1.3\% of pregnant women in 2011-2012. This rate was similar to the level in patients admitted to hospital for planned surgery or in household contact with $\mathrm{CHCV}$ patients. It could be suggested that anti-HCV rate of $1 \%$ reflected an average frequency of 
chronic asymptomatic HCV infection in the population of the Russian Federation.

In different territories, the prevalence of anti-HCV in pregnant women varied greatly. This is a sign of different intensities of HCV spread in risk groups. For example, high anti-HCV rates $(>2 \%)$ were reported in 15 territories of the country in 2010. These territories also reported CHCV incidence and prevalence rates higher than the average rate in the country. It can indirectly indicate the existence of correlation between frequency of anti-HCV and $\mathrm{CHCV}$ prevalence. Possibly, the rising probability of transmitting HCV from mothers to their newborn children cannot be excluded.

It is also very interesting to analyze results of anti-HCV tests in persons admitted to hospital for planned surgery. In 2011-2013, anti-HCV rates in this group were similar $(1.5 \%-1.6 \%)$. It is important to note that this index was two times higher than the frequency of hepatitis B surface antigen (HBsAg) in the same group of patients. Perhaps, it can be explained by accumulation of more patients chronically infected with $\mathrm{HCV}$ in comparison with patients with chronic hepatitis B virus (HBV) infection because of the higher potential of $\mathrm{HCV}$ to produce chronic infection. In 2011-2013, the highest levels of anti-HCV in planned surgery patients were found in the Central Federal Territory (1.7\%), Far East (2.1\%), and Ural (3.3\%). The latter two federal territories also reported highest rates of $\mathrm{CHCV}$ incidence and prevalence.

\section{Molecular epidemiology}

One of the first important studies concerning HCV genotypes distribution in Russia was published by researchers from Moscow Institute of Virology in $1996 .^{7}$ They demonstrated that five virus subtypes (1a, 1b, 2a, 2b, and 3a) circulated in the Russian Federation with significant domination of HCV1b (68.9\%). These data were confirmed in 1997 by another independent group that revealed HCV1b subtype in $76 \%$ of $\mathrm{HCV}$ patients who were tested. ${ }^{8} \mathrm{~A}$ special study of HCV genotypes in St Petersburg in 1999-2000 showed statistically significant differences in HCV subtype distribution between $\mathrm{HCV}$ cases in patients attending infectious diseases clinics and in dialysis patients. ${ }^{6}$ Five subtypes (3a, $1 \mathrm{~b}, 1 \mathrm{a}, 2 \mathrm{a}$, and $4 \mathrm{a}$ [in order of frequency]) were found in outpatients, while three subtypes (1b, 3a, and 2c) circulated in dialysis patients. Subtype 3a was the dominant subtype in outpatients ( $51 \%$ of cases), followed by subtype $1 \mathrm{~b}(40 \%$ of cases). It was noted that in St Petersburg, 56\% of patients with $\mathrm{HCV}$ who attended infectious disease clinics were between 11 years and 20 years of age, $63 \%$ of whom were infected with subtype $3 \mathrm{a}$ and only $33 \%$ with subtype $1 \mathrm{~b}$.
However, among patients older than 20 years, subtype $1 \mathrm{~b}$ was prevalent (49\%), followed by subtype 3a (36\%). Most of the patients with HCV3a were reported as drug addicts. These data were also confirmed by other authors. ${ }^{9}$ Subtype $1 \mathrm{~b}$ was dominant in all dialysis patients and accounted for $89 \%$ of cases.

Later, researchers from St Petersburg demonstrated the recombination of natural intergenotypes between subtypes $2 \mathrm{k}$ and $1 \mathrm{~b}$, designated as $\mathrm{RF} \_2 \mathrm{k} / 1 \mathrm{~b} .{ }^{10}$ The finding of a $2 \mathrm{k} / 1 \mathrm{~b}$ recombinant strain in $5 \%$ of $\mathrm{HCV}$-infected patients in St Petersburg has shown that this particular recombinant $\mathrm{HCV}$ strain was not only viable but had also spread in the city. This $\mathrm{HCV}$ strain was also revealed in different regions of Russia and other countries evidenced its wide spread. ${ }^{11-14}$ The latest data on distribution of HCV genotypes published in 2012 confirmed results of previous research, ${ }^{15} \mathrm{ie}$, the domination of HCV1b subtype in general population $(57.1 \%)$ as in hemodialysis patients (83.6\%). The second rank belonged to HCV3a in both studied groups (29.7\% and $16.4 \%$, respectively). Similar data were reported by other research groups. ${ }^{16}$

\section{Discussion and conclusion}

$\mathrm{HCV}$ continues to remain one of the main problems in the public health sector in the Russian Federation. Currently, the manifestations of an epidemic process of $\mathrm{HCV}$ based on data of registers of acute and chronic forms of HCV has undergone significant changes. It was established that HCV epidemiological features are characterized by:

- low incidence of AHCV cases in all territories of the country (from $22.2 / 100,000$ in 2001 to $1.5 / 100,000$ in 2013, ie, more than 14 times);

- increase in registration (incidence) of newly detected chronic cases of infection (from 12.9/100,000 in 1999 to $39.3 / 100,000$ in 2013 , ie, more than three times);

- a significant increase in cumulative rate of CHCV cases (prevalence) that reached 335.8/100,00 and in most administrative territories, higher in specific age groups (30-49 years);

- low HCV incidence and prevalence in children in comparison with adults;

- a rise in HCV rates in specific population groups (newborns from chronically infected mothers, persons from correctional facilities, patients with chronic liver diseases, and clients from clinics for STD patients and drug users);

- the use of molecular-genetic methods in epidemiological diagnostics for $\mathrm{HCV}$, that will make it possible to reliably establish the source of the infection, routes, and factors of transmission; and 
- domination of HCV1b virus subtype and rising importance of HCV3a subtype and newly designated recombinant RF_2k/1b.

All the aforementioned data are extremely important for planning and implementation of primary, secondary, and tertiary preventive measures for the control of HCV infection in the Russian Federation. Special attention should be paid to treatment of $\mathrm{CHCV}$ patients.

\section{Acknowledgment}

The authors would like to express their gratitude to Dr Nikolai Chaika for assistance with manuscript preparation.

\section{Disclosure}

The authors report no conflicts of interest in this work.

\section{References}

1. Choo QL, Kuo G, Weiner AJ, Overby LR, Bradley DW, Houghton M. Isolation of a cDNA clone derived from a blood-borne non-A, non-B viral hepatitis genome. Science. 1989;244(4902):359-362.

2. WHO. WHO-Recommended Standards for Surveillance of Selected Vaccine-Preventable Diseases. Geneva: WHO; 2003. [WHO/V\&B/03.01].

3. The Federal Structure: National Voting on December 12, 1993: Art. In: The Constitution of the Russian Federation. Meeting of the legislation of the Russian Federation. 2014;31:65-79.

4. Mukomolov SL, Levakova IA. Epidemiological characteristics of chronic viral hepatitis in Russian Federatoin in 1999-2009. J Infect and Immun. 2011;1(3):255-262.

5. Pimenov NN, Chulanov VP, Komarova SV, et al. Hepatitic C in Russia: current epidemiology and approaches to improving diagnosis and surveillance. Epidemiol Infect Dis. 2012;17(3);4-10.
6. Kalinina $\mathrm{O}$, Norder $\mathrm{H}$, Vetrov $\mathrm{T}$, et al. Shift in predominating subtype of $\mathrm{HCV}$ from $1 \mathrm{~b}$ to $3 \mathrm{a}$ in St. Petersburg mediated by increase in injecting drug use. J Med Virol. 2001;65(3):517-524.

7. Lvov DK, Samokhvalov EI, Tsuda F, et al. Prevalence of hepatitis C virus and distribution of its genotypes in Northern Eurasia. Arch Virol. 1996;141:1613-1622.

8. Viazov S, Kuzin S, Paladi N, et al. Hepatitis C virus genotypes in different regions of the former Soviet Union (Russia, Belarus, Moldova and Uzbekistan). J Med Virol. 1997;53:36-40.

9. Paintsil E, Verevochkin S, Dukhovlinova E, et al. Hepatitis C virus infection among drug injectors in St.Petersburg, Russia: social and molecular epidemiology of an endemic infection. Addiction. 2009;104(11):1881-1890.

10. Kalinina O, Norder H, Mukomolov S, Magnius LO. A natural intergenotypic recombinant of hepatitis $\mathrm{C}$ virus identified in St. Petersburg. J Virol. 2002;76(8):4034-4043.

11. Tallo T, Norder H, Tefanova V, et al. Genetic characterization of hepatitis $\mathrm{C}$ virus strains in Estonia: fluctuations in the predominating subtype with time. J Med Virol. 2007;79(4):374-382.

12. Kurbanov F, Tanaka Y, Avazova D, et al. Detection of hepatitis $C$ virus natural recombinant RF1_2k/1b strain among intravenous drug users in Uzbekistan. Hepatol Res. 2008;38(5):457-464.

13. Demetriou VL, van de Vijver DA; Cyprus HCV Network, Kostrikis LG. Molecular epidemiology of hepatitis $\mathrm{C}$ infection in Cyprus: evidence of polyphyletic infection. J Med Virol. 2009;81(2):238-248.

14. Avó AP, Agua-Doce I, Andrade A, Pádua E. Hepatitis C virus subtyping based on sequencing of the $\mathrm{C} / \mathrm{E} 1$ and NS5B genomic regions in comparison to a commercially available line probe assay. J Med Virol. 2013;85(5):815-822.

15. Mukomolov SL, Levakova IA, Suliagina LG, Sinaiskaya EV, Bolsun DD, Ivanova NV. Current epidemiology of hepatitis C in Russia. Epidemiol Infect Dis. 2012;17(6):21-25.

16. Ilina EN, Malakhova MV, Generozov EV, Nikolaev EN, Govorun VM. Matrix-assisted laser desorption ionization-time of flight (mass spectrometry) for hepatitis C virus genotyping. J Clin Microbiol. 2005;43(6):2810-2814.
Hepatic Medicine: Evidence and Research

\section{Publish your work in this journal}

Hepatic Medicine: Evidence and Research is an international, peerreviewed, open access journal covering all aspects of adult and pediatric hepatology in the clinic and laboratory including the following topics: Pathology, pathophysiology of hepatic disease; Investigation and treatment of hepatic disease; Pharmacology of drugs used for

\section{Dovepress}

the treatment of hepatic disease. Issues of patient safety and quality of care will also be considered. The manuscript management system is completely online and includes a very quick and fair peer-review system, which is all easy to use. Visit http://www.dovepress.com/ testimonials.php to read real quotes from published authors. 